IZA DP No. 4927

Individual Determinants of Work Attendance:

Evidence on the Role of Personality

Susi Störmer

René Fahr

May 2010 


\title{
Individual Determinants of Work Attendance: Evidence on the Role of Personality
}

\author{
Susi Störmer \\ University of Hamburg \\ René Fahr \\ University of Paderborn \\ and IZA
}
Discussion Paper No. 4927
May 2010
IZA
P.O. Box 7240
53072 Bonn
Germany
Phone: +49-228-3894-0
Fax: +49-228-3894-180
E-mail: iza@iza.org

Any opinions expressed here are those of the author(s) and not those of IZA. Research published in this series may include views on policy, but the institute itself takes no institutional policy positions.

The Institute for the Study of Labor (IZA) in Bonn is a local and virtual international research center and a place of communication between science, politics and business. IZA is an independent nonprofit organization supported by Deutsche Post Foundation. The center is associated with the University of Bonn and offers a stimulating research environment through its international network, workshops and conferences, data service, project support, research visits and doctoral program. IZA engages in (i) original and internationally competitive research in all fields of labor economics, (ii) development of policy concepts, and (iii) dissemination of research results and concepts to the interested public.

IZA Discussion Papers often represent preliminary work and are circulated to encourage discussion. Citation of such a paper should account for its provisional character. A revised version may be available directly from the author. 
IZA Discussion Paper No. 4927

May 2010

\section{ABSTRACT \\ Individual Determinants of Work Attendance: Evidence on the Role of Personality}

We investigate the influence of personality as measured by the Big Five personality scale on absenteeism using representative data for Germany. In particular, the 2005 wave of the German Socio-Economic Panel provides detailed information on socio-economic background characteristics along with a Big Five personality scale. Estimates of a Logit model and of count data regression are used to analyze an empirical model based on the theory of hedonic labour market outcomes. These estimates allow us to test hypotheses on the influence of the Big Five personality traits on work attendance. We find clear negative correlations between the probability to be absent and Conscientiousness as well as Agreeableness. We find a strong positive impact of Neuroticism on work attendance decisions in general and clues for a positive impact of Extraversion among men. When looking at the length of absence occurrences the personality dimensions of Neuroticism and Agreeableness are found to significantly influence male absenteeism. Implications of our results are discussed.

JEL Classification: J20, M12, M51

Keywords: absenteeism, Five Factor Model, personality, count data model

Corresponding author:

René Fahr

University of Paderborn

Faculty of Business Administration and Economics

Warburger Strasse 100

33098 Paderborn

Germany

E-mail: rene.fahr@wiso.uni-paderborn.de 


\section{Introduction}

The estimated costs of employee absence are high. Despite the current and historically lowest absence rates to be observed in Germany, several firms have to deal with diminished profits due to absenteeism, e.g. in 2007 sick pay expenditures of German employers amounted to ca 31 billion Euro (Destatis 2009).

Information about the determinants of absenteeism is valuable for firms and policy makers. However, a recent study concludes after analyzing an extraordinary rich set of explanatory variables for the determinants of absenteeism that "most of the cross-sectional variation in absenteeism is ultimately 'explained' by unobserved timeinvariant individual characteristics" (Markussen et al., 2009, p. 33). We investigate personality - measured by a Big Five personality scale (McCrae and John 1992) - as an important individual determinant of attendance decisions.

Personality measures have been researched as explanatory constructs and predictors of attitudes, work behaviours, and outcomes in the organizational setting in numerous primary studies and meta-analyses in the last two decades. This research indicates strong support for the use of personality assessment in staffing decisions, particularly in personnel selection (Ones et al., 2007). By emphasizing the link between personality measures and work attendance as an obvious measure of productivity, the present article contributes to this literature.

The psychological literature on absenteeism was prevalently concerned with negative work attitudes, e.g. job satisfaction and organizational commitment. As absenteeism represents a specific behaviour whereas work attitude is a more general construct, attitudes are likely to be insufficient as explanatory variables of absenteeism (Martocchio and Harrison, 1993). A particular problem in this literature is the fact that it is difficult to come up with a precise definition of the variables and constructs (Barmby et al., 1991). Therefore, relatively stable characteristics like personality traits might be a fruitful way to explain absenteeism as was proposed by several researchers (Harrison and Martocchio, 1998).

The economic approaches explain absenteeism for example as the result of an equilibrium outcome given individual labour-leisure preferences in a standard labour 
supply model (Allen, 1981). Barmby and Treble (1991) and Barmby et al. (1991) point out that the optimal outcome is also influenced by the labour demand side in form of workplace conditions like the number of contracted hours, wages and components of the institutional setting (e.g. sick pay). This is more explicit in shirking models where high wages or high unemployment rates discourage voluntary absenteeism because of the costs of being dismissed when being caught for malfeasant absence (Barmby et al., 1994).

A suitable economic framework to analyze the influence of workers' characteristics on absenteeism is provided by the theory of hedonic labour market outcomes (Rosen, 1986). We follow Delgado and Kniesner (1997) who presented a reduced form of this model describing the labour market equilibrium as the matches of wage and nonwage characteristics of employment between firms and workers. Accordingly, we estimate the inverse hedonic market equilibrium in the form that the absence rate is a function of workplace and worker characteristics with workers' personality traits in particular.

By analyzing data from the German Socioeonomic Panel (GSOEP) - a representative dataset for Germany - our study contributes unique evidence to the literature on the influence of personality on absenteeism. In particular, with 4,901 observations we exceed the number of observations that Salgado (2002) has in his meta-study on the influence of the Big Five on counterproductive behaviour by two to three times. ${ }^{1}$ To our knowledge there are only two case studies in the literature relating the Big Five to absenteeism. Judge et al. (1997) have 89 observations of nonacademic university staff members while Darviri and Woods (2006) investigate the absence behaviour of 128 clerical workers from the Greek construction industry.

Current research by Borghans et al. (2008) emphasizes the importance of the linkage between personality measures from psychology and economic preferences such as time preferences and risk aversion, and economic outcomes in general. A key

\footnotetext{
${ }^{1}$ The studies meta-analyzed by Salgado (2002) do not all include all Big Five personality factors. While twelve studies include a measure of Emotional Stability (the positive pole of Neuroticism), ten studies include measures of Extraversion and Conscientiousness, and only eight studies include measures of Openness to Experience and Agreeableness. Accordingly, the numbers of observation in the metaanalysis differ depending on the personality factor under study.
} 
issue is the predictive power of personality measures with respect to economic outcomes. Heckman et al. (2006) show that the predictive power of personality traits for occupational choice and wages exceeds the predictive power of cognitive traits which are investigated in much more detail in the hitherto existing economic literature. Nyhus and Pons (2005) using representative data for the Netherlands find evidence that a specific personality trait (Emotional Stability) predicts higher wages. For Germany, Heineck and Anger (2008) investigate the influence of personality traits on wages using data of the GSOEP. The findings are with respect to gender differences heterogeneous.

The article is organized as follows. In the next section we describe some background on personality and absenteeism research and propose hypotheses regarding the influence of the Big Five personality traits on work attendance behaviour. In section 3 an empirical model of worker absenteeism is presented; the data and selected sample are described in section 4. Section 5 presents results and section 6 contains discussion and conclusion.

\section{The Psychology of Personality and Work Attendance}

Personality has become a popular research topic for scientists from various disciplines as it appears to influence most aspects of human interaction. The Five Factor Model forms a hierarchical concept that encompasses five independent and stable personality dimensions (Big Five ${ }^{2}$ ) which allow the differentiation among people by studying their individual ratings on the respective scales. Typically, these dimensions are referred to as Extraversion, Neuroticism, Conscientiousness, Agreeableness and Openness to Experience (Costa and McCrae, 1992). ${ }^{3}$

The Big Five personality dimensions were typically considered to be stable after age 30 (McCrae and Costa, 2003). This view is challenged by a recent meta-analysis of 92 studies by Roberts et al. (2006) who find significant mean-level changes for most personality dimensions after the age of 30 . However, the differential continuity of

\footnotetext{
${ }^{2}$ The term "Big Five" has been coined by Goldberg (1981) to emphasize the high abstraction level of the five personality factors.

${ }^{3}$ See John and Srivastava (1999) for an overview on the history and theoretical perspectives of the Big Five trait taxonomy.
} 
personality traits, i.e. the stability of individual differences in scores, is remarkable and changes in absolute terms do not necessarily contradict the relative continuity of personality traits (Mc Adams, 2006). As a result, "much of the confusion over changeability of personality in adulthood is attributable to the imprecise use of the terms continuity and change" (Caspi, 1999, p. 319).

When applying the theory of personality traits to absenteeism research, it is reasonable to assume that differences in attendance behaviour could be explained by differences in personality which in turn impact the hedonic locus in the labour market model. First research results in this direction were presented by Sinha (1963) who found a significant positive relationship between absenteeism and manifest anxiety among industrial workers. Porter and Steers (1973) found that emotionally instable and anxious as well as independent, self-confident and aggressive employees tend to be absent more often.

The influence of personality on absenteeism using the Five Factor Model has been investigated in only a few studies with small sample sizes and ambiguous results (see e.g. Judge et al., 1997; Darviri and Woods, 2006). Therefore, the analysis of a representative sample is a promising undertaking. In the next paragraphs we develop hypotheses for the specific personality domains by relating to the research in this area.

Extraversion. Typically, extraverts are outgoing, active, positively emotional (John and Srivastava, 1999), maintain their social contacts and desire a varied leisure and work time (Pervin et al., 2005). Usually, the working life might put restrictions on their ability to fully live their extravert lifestyle which could lead to the conclusion that leisure time is more valuable to extraverts. Following the income-leisure-model of Allen (1981), being absent extends the leisure time of extraverted people. This is similar to the line of argument by Judge et al. (1997) who reason that working time constitutes a barrier to leisure activities with friends and family. Furthermore, Erdheim et al. (2006) found a negative influence of Extraversion on continuance commitment, which leads to the assumption that potential negative consequences of absence are valued less. Therefore, we expect that extraverted employees exhibit higher absenteeism rates than less extraverted employees. 
Hypothesis 1: Extraverted employees exhibit higher rates of absenteeism (H1).

Neuroticism. People scoring high on Neuroticism tend to be anxious, nervous, frustrated and blame themselves (McCrae and John, 1992). Moreover, neurotic people tend to be overcommitted which causes them to take their work very serious, for example working even in leisure time although it is not necessary (Vearing and Mak, 2007). While overcommitment would in principle lead to lower absence rates, it was found that overcommitment has a negative influence on several aspects of health, especially as a promoter of depression symptoms (Vearing and Mak, 2007). Absence due to mental or physical illness could be the consequence. This is likely to counteract the expected negative influence from higher continuance commitment. Additionally, Martocchio and Harrison (1993) suggest that neurotic people feel so much pressure in their jobs that absence can be seen as part of a coping strategy. We presume that the negative consequences of overcommitment prevail, leading to higher absenteeism rates (due to mental illness) among neurotic employees.

Hypothesis 2: Neurotic employees exhibit higher rates of absenteeism (H2).

Conscientiousness. Conscientious people are organized, show responsibility for themselves and others, are reliable and think before they act (John and Srivastava, 1999). Furthermore they are achievement-oriented, persevering and hard working (Barrick and Mount, 1991). Barrick and Mount (1991) found a positive relationship between Conscientiousness and job performance, suggesting that conscientious people are more successful in their jobs. We assume that high job performance is basically dependent upon attendance and therefore requires low absenteeism rates. This is supported by the work of Hogan und Ones (1997) proposing conscientious employees to be more productive, hard working and avoiding counterproductive behaviour than less conscientious employees.

Hypothesis 3: Conscientious employees exhibit lower rates of absenteeism (H3).

Agreeableness. Agreeableness implies a prosocial and collectivistic orientation towards others, causing agreeable people to be altruistic, thankful and modest (John and Srivastava, 1999). Transferred to the work environment this should lead to lower absenteeism rates. This is supported by the results of a study by Erdheim et al. (2006) 
who found a significant positive influence of Agreeableness on normative commitment. Thus, agreeable people might feel a greater obligation towards their employer and we assume that this leads to less counterproductive behaviour such as absenteeism. This is in contrast to theoretical arguments and evidence presented by Seibert and Kraimer (2001) showing a negative correlation between Agreeableness and career satisfaction. If low career satisfaction impacts the worker's loyalty towards the employer negatively, we would expect more agreeable employees to exhibit higher rates of absenteeism. However, we hypothesize an overall negative correlation between Agreeableness and absenteeism caused by the prosocial orientation of agreeable employees. We account for a possible indirect negative effect of Agreeableness as the result of lower levels of career satisfaction by including a measure of workers' job satisfaction as a control variable.

Hypothesis 4: Agreeable employees exhibit lower rates of absenteeism (H4).

Openness to Experience. Openness can be related to the need for novelty, variety and complexity as well as the intrinsic desire for experience (McCrae, 1996). If workers scoring high on the factor Openness end up in a workplace which is characterized by routine, boredom at work and a low degree of autonomy, their absence rates might be higher. Due to the complexity of the dimension Openness, comprising among others a possibly attendance friendly scale (e.g. values, which in turn could influence aspects of organizational commitment) we refrain from stating an explicit hypothesis for this personality domain.

\section{An Empirical Model of Worker Absenteeism}

The relevant economic mechanism for our empirical model is provided by the theory of hedonic labour market outcomes (Rosen, 1986) which links the observed absenteeism to personal and job characteristics. To be more precise, "the matching of workers and firms in the labour market produces a locus of wage-absenteeism pairings" (Delgado and Kniesner, 1997, p. 41) which is determined by personal characteristics and personal traits of the workers, firm characteristics as well as the macroeconomic environment of the particular labour market. Because we are 
interested in the determinants of work attendance rather than the wage we follow Delgado and Kniesner (1997) and estimate the inverse hedonic locus as

$$
a_{i}=f^{-1}\left(W_{i}, C_{i}, S_{i}, P_{i}, D_{i}, \varepsilon_{i}\right)
$$

with $a$ as the absence rate, $W$ denoting the hourly wage, $C$ as the vector of nonwage characteristics of the employment relationship, $S$ as a vector including variables on the socio-economic background of the worker, and $P$ as a measure of personality including the Big Five personality factors. ${ }^{4} D$ denotes workplace and employer related information, while $\varepsilon$ represents a stochastic error term. We will be more precise about the assumed distribution below. By using count data regressions to estimate equation (1) we follow Delgado and Kniesner (1997) and Barmby et al. (2001) among others.

We estimate a linear exponential specification of the absence rate to ensure nonnegative conditional expectations:

$$
E\left(a_{i} \mid X_{i}\right)=\exp \left(X_{i}^{\prime} \beta_{0}\right)
$$

where the vector $X_{i}$ includes all explanatory variables mentioned in equation (1). Under the assumption that $a_{i}$ given $X_{i}$ follows a Poisson distribution, the resulting model is referred to as the Poisson regression model and can be estimated by maximum likelihood (ML). Because this distributional assumption implies that the conditional variance of $a_{i} \operatorname{Var}\left(a_{i} \mid X_{i}\right)$ equals the conditional mean as in equation (2), more flexible distributions have been suggested to allow for the variance to be different from the mean. Possible solutions suggested in the literature are the Nebgin I and the Negbin II model (Cameron and Trivedi, 1998; Winkelmann, 1997). As the latter has proven to be most useful in empirical applications (Cameron and Trivedi, 2005) and in count data estimates of absenteeism in particular (Winkelmann, 1999; Barmby et al., 2001), we will estimate a Negbin II model in the following. The variance in the Negbin II model is estimated as

$$
\operatorname{Var}\left(a_{i} \mid X_{i}\right)=\left(1+\alpha \exp \left(X^{\prime} \beta\right)\right) \exp \left(X_{i}^{\prime} \beta\right)
$$

with the attribute of a quadratic relationship between the expected mean and the variance. This allows for overdisperson, i.e. the variance exceeds the expected mean;

\footnotetext{
${ }^{4}$ According to the focus of the present article we list the personality characteristics $(P)$ separately from the other personal characteristics of the worker (S).
} 
and is the reason for labelling it Negbin $11 .{ }^{5}$ Term (3) reduces to the variance in the Poisson model if $\alpha=0$ which will be tested in the results section. The parameter $\alpha$ measures the amount of dispersion and is increasing with the conditional mean. An additional beneficial feature of the Negbin II ML estimation of the vector $\beta$ is its robustness to distributional misspecification. The associated ML standard errors are, however, inconsistent if there is any distributional misspecification. The estimated coefficients allow for the neat interpretation of a semi-elasticity in the case of continuous explanatory variables $x_{i j}$. The coefficient $\beta_{j}$ equals the proportionate change in the conditional mean if the $j^{\text {th }}$ regressor changes by one unit (Cameron and Trivedi, 1998). The exponent of the coefficient of a binary variable $d_{i k}, \exp \left(\beta_{k}\right)$, provides the ratio between the expectations of $a_{i}$ given $d_{i k}=1$ and $d_{i k}=0$. Besides our preferred Nebgin II count data model we estimate a Logit model to investigate the determinants of reporting any days of absence at all. By this we reply to the legitimate objection that the self reported days of absence might result in a huge measurement error in the dependent variable. On the other hand, the occurrence of being absent for at least one day is likely to be influenced more strongly by random events unrelated to specific personal characteristics. We estimate two specifications: (1) A parsimonious specification including the Big Five personality factors as well as measures of the health condition and one-year lagged absenteeism and (2) a specification including further controls for the socio-economic background of the individuals, workplace and employer characteristics as well as satisfaction variables (satisfaction with work, leisure, and income). While the first specification will naturally suffer from omitted variable bias we think that this specification might be informative to evaluate the relative importance of personality for absenteeism, in particular, compared to personal and workplace characteristics.

\section{Data, Sample Selection and Methods}

We use data from the waves of 2004 to 2006 of the German Socio-Economic Panel (GSOEP). Among detailed information about the socio-economic background of

\footnotetext{
${ }^{5}$ Within the Negbin I model by Cameron and Trivedi (1986) the variance has a linear relationship with the expected mean.
} 
individual and workplace characteristics the questionnaire in the year 2005 includes a 15-item scale to measure the Big Five with three items each (see Table A 1 in the annex for details). This relatively brief personality scale BFI-S has been developed and validated to be used in the GSOEP and satisfies the needs of an extensive representative survey (Gerlitz and Schupp, 2005). ${ }^{6}$ We standardize the Big Five values before including them into the analysis.

To account for possible age related mean-level changes in the personality traits we include the personality scores in an age adjusted form. Following an approach by Nyhus and Pons (2005) and adopted by Heineck and Anger (2008), we therefore regress each personality trait on age and age squared and include the standardized residual from this regression into our empirical analysis.

In line with Winkelmann and Winkelmann (2008) we further dispense with the analysis of panel data which are available for the other variables but the personality measure to avoid the introduction of a measurement error if personality is not timeinvariant through adult life. Furthermore, there appear to exist gender related differences in personality between men and women in that women score higher on the Neuroticism and Agreeableness scale (Costa et al., 2001). Because significant differences in measured personality are also present in our data ${ }^{7}$, and we expect the influence between personality and absenteeism to differ structurally by gender, we provide separate analyses for men and women in addition to the analysis for the total sample.

We exclude employees with nonstandard work contracts or any physical attributes, which might directly influence absence behaviour. In particular, we exclude self-employed, apprentices and interns as well as physically or mentally disabled employees.

\footnotetext{
${ }^{6}$ In fact, to further explore the validity of the given personality scale we have conducted a factor analysis with the 15 personality items in the questionnaire. The analysis yielded five factors explaining more than $60.2 \%$ of the variance in the personality items. According to the Kaiser-Meyer-Olkin (KMO) measure of sampling adequacy (overall $\mathrm{KMO}=75.5$ ) all items are factorizable which demonstrates the strength of the given personality measure.

${ }^{7}$ The standardized average scores for the Big Five dimensions by gender are as follows (men/women): Extraversion (-0.1646/0.1354), Neuroticism (-0.2578/0.1213), Conscientiousness (-0.0151/0.1383), Agreeableness (-0.1975/0.1738), Openness to Experience (-0.0904/0.0720). All gender related differences in the Big Five personality dimensions are highly significant according to t-tests.
} 
Work attendance is measured by the variable days absent 05 containing selfreported information about the number of days absent from work in 2005 including days absent without any medical certification. This variable is taken from the wave of 2006. Further, we use the dummy variable absent 05 as an indicator if an employee records any days of absence at all.

To account for a number of other variables that have shown to potentially influence absenteeism we include several control variables into our analysis. Past absenteeism has shown to be a very strong predictor to absenteeism (Harrison and Martocchio, 1998; Cohen and Golan, 2007) which is why we include the previous year's absenteeism information into our analysis, i.e. the days absent 04 in the Negative Binomial regression and a dummy variable absent 04 in the Logit model respectively. Information on the health status of the individual is obtained from a selfreported score on the satisfaction with one's own health measured on a 10-point Likert scale. $^{8}$

Further, the GSOEP provides us with an enormous set of variables concerning the socioeconomic background of the individuals (including measures of human capital), characteristics of the workplace and the employer (including firm size and industry) and measures of satisfaction in various areas of life.

Health satisfaction as well as variables measuring satisfaction with other conditions of life (e.g. work, income) and hourly wage might be endogenous with the personality measures in so far as the working conditions and the personal and social life and their respective evaluation feed back to personality (Heineck and Anger, 2008). To account for this source of endogeneity we include the health variable, controls for the hourly wage as well as satisfaction variables in various areas of life in their lagged form into the analysis (i.e. from the wave of 2004) while all other control variables are taken from the wave of 2005.

\footnotetext{
${ }^{8}$ The GSOEP also contains a variable on the current health constitution which is measured on a fivepoint scale. We prefer the chosen variable since "satisfaction with one's own health" is more likely to influence decisions on absence in the long-term than does the actual health constitution. In line with the work of Barmby et al. (1994) an unchanged health constitution can lead to different absence behaviour. Furthermore, we appreciate the higher level of distinction that is provided by a 10-point scale.
} 
Given that the GSOEP data allow the analysis of a large number of observations and the fact that missing observations might be the result of selective under-reporting we exclude any observations with missing values. This leaves us with a sample of 4091 observations, consisting of $47.5 \%$ female and $52.5 \%$ male representative employees of the German workforce. For a list and descriptive statistics of all variables see Table A 2 in the annex.

\section{Results}

\section{Descriptive Statistics}

When reviewing some descriptive statistics displayed in Table 1 it already seems that personality matters. Comparing the average probability to be at least one day absent and the average number of days absent for employees that score above the mean value of the Big Five personality factors of Neuroticism, Conscientiousness, and Agreeableness with the respective average value of workers scoring below the average value of these personality factors, the observed values for the work attendance variable differ significantly according to t-tests. However, significant differences regarding the number of days absent cannot be found for the female sample - except for the Neuroticism dimension.

In the pooled sample we observe that for those employees scoring above average on the Neuroticism dimension the probability of reporting at least one day of absence is on average $4.4 \%$ higher than for those employees scoring below average. Male employees have on average 1.85 days more of absence when being neurotic above average while more neurotic female employees have even 2.02 days more of absence than less neurotic employees. When looking at the absence data of above average conscientious and agreeable employees we find a mirror image for the propensity of absence. Higher Conscientiousness is associated with a highly significant decrease in the average absence rate by $5-6 \%$ in all samples and an even slightly higher decrease rate (6-7\%) for the Agreeableness dimension. For Extraversion no significant differences in the attendance variables are present. Gender-specific mixed evidence is found for Openness. We find that the absence rates and number of days absent rise for 
women with above average scores on this dimension, while they decline for men. These ambiguous results are in line with our decision to refrain from stating a hypothesis for the Openness dimension.

Table 1: Absence by diverse characteristics

\begin{tabular}{|c|c|c|c|c|c|c|}
\hline \multirow[b]{2}{*}{ Variable } & \multicolumn{2}{|c|}{ Total Sample } & \multicolumn{2}{|c|}{ Female } & \multicolumn{2}{|c|}{ Male } \\
\hline & Absent 05 & $\begin{array}{c}\text { Days } \\
\text { absent05 }\end{array}$ & Absent 05 & $\begin{array}{c}\text { Days } \\
\text { absent05 }\end{array}$ & Absent 05 & $\begin{array}{c}\text { Days } \\
\text { absent05 }\end{array}$ \\
\hline Mean & 0.5572 & 7.3609 & 0.5631 & 7.9090 & 0.5519 & 6.8643 \\
\hline Standard Deviation & $(0.4968)$ & $(17.7095)$ & $(0.4961)$ & $(19.5662)$ & $(0.4974)$ & $(15.8275)$ \\
\hline Extraversion $\geq \varnothing$ & 0.5651 & 7.5679 & 0.5667 & 8.4957 & 0.5617 & 6.8680 \\
\hline Extraversion $<\varnothing$ & 0.5490 & 7.1448 & 0.5601 & 7.4218 & 0.5439 & 6.8612 \\
\hline $\mathrm{p}$-value (t-test) & 0.2575 & 0.4031 & 0.7491 & 0.1872 & 0.3672 & 0.9914 \\
\hline Neuroticism $\geq \varnothing$ & 0.5790 & 8.6558 & 0.5793 & 8.9728 & 0.5801 & 7.7368 \\
\hline Neuroticism $<\varnothing$ & 0.5355 & 6.0677 & 0.5485 & 6.9527 & 0.5202 & 5.8844 \\
\hline $\mathrm{p}$-value (t-test) & $0.0022 * * *$ & $0.0000 * * *$ & 0.1342 & $0.0128^{* *}$ & $0.0023^{* * *}$ & $0.0030 * * *$ \\
\hline Conscientiousness $\geq \varnothing$ & 0.5269 & 7.5434 & 0.5365 & 8.1175 & 0.5311 & 6.9664 \\
\hline Conscientiousness $<\varnothing$ & 0.5870 & 7.1832 & 0.5931 & 7.6743 & 0.5849 & 6.7025 \\
\hline $\mathrm{p}$-value (t-test) & $0.0000^{* * *}$ & 0.4766 & $0.0060 * * *$ & 0.5853 & $0.0075^{* * *}$ & 0.6806 \\
\hline Agreeableness $\geq \varnothing$ & 0.5235 & 6.9738 & 0.5332 & 7.5611 & 0.5195 & 6.0548 \\
\hline Agreeableness $<\varnothing$ & 0.5897 & 7.7340 & 0.6026 & 8.3685 & 0.5900 & 7.8140 \\
\hline $\mathrm{p}$-value (t-test) & $0.0000^{* * *}$ & 0.1330 & $0.0008 * * *$ & 0.3240 & $0.0003^{* * *}$ & $0.0049 * * *$ \\
\hline Openness $\geq \varnothing$ & 0.5564 & 7.6077 & 0.5738 & 9.1605 & 0.5385 & 6.0074 \\
\hline Openness $<\varnothing$ & 0.5581 & 7.1132 & 0.5507 & 6.4705 & 0.5639 & 7.6248 \\
\hline$p$-value (t-test) & 0.9081 & 0.3284 & 0.2624 & $0.0009 * * *$ & 0.1960 & $0.0097^{* * *}$ \\
\hline Health $\geq \varnothing$ & 0.5097 & 5.6381 & 0.5115 & 5.9876 & 0.5082 & 5.3436 \\
\hline Health $<\varnothing$ & 0.6052 & 9.1000 & 0.6113 & 9.7060 & 0.5992 & 8.5093 \\
\hline $\mathrm{p}$-value (t-test) & $0.0000 * * *$ & $0.0000 * * *$ & $0.0000 * * *$ & $0.0000 * * *$ & $0.0000 * * *$ & $0.0000 * * *$ \\
\hline
\end{tabular}

Notes: Own calculations with GSOEP 2004-2006. $\mathrm{N}=4901$. " $\varnothing$ " refers to the average value of the specific characteristic in the respective samples (e.g. the standardized mean value of Neuroticism is 0.1218 for women while it is -0.2677 for men. $\mathrm{H}_{0}$ of the two-sided t-test: There are no differences between the average values of the absence probability (respectively days absent) if the value of the specific characteristic is greater or equal to the average value in comparison to a value smaller than the average value of the specific characteristic. ${ }^{* * *}\left(* *,{ }^{*}\right): \mathrm{H}_{0}$ is rejected at a significance level of $1 \%(5 \%, 10 \%)$.

When finally looking at the average absence data of above average healthy employees we find clear evidence that subjective health might play an important role on attendance decisions since above average healthy employees exhibit an about $10 \%$ lower probability of being at least one day absent from work and have on average more than three days less of absence than above average healthy employees. At this 
stage we cannot say whether we observe influences of personality per se or rather effects driven by the correlation of the personality factors with other important determinants of absenteeism.

\section{Estimation Results}

When reviewing the marginal effects of the Logit regression of specification (1) and the full model in Table 2 we observe that personality matters concerning the attendance decision. Similar to the results of the descriptive analysis we find supporting evidence for three of our four hypotheses but observe gender specific effects for the dimensions of Neuroticism, Conscientiousness and Agreeableness.

For the dimension of Extraversion a weakly significant positive impact on the probability to be absent at least one day is found for the male sample only providing some evidence in favour of $\mathrm{H} 1$. If the Extraversion score of a male employee increases by one standard deviation, the average absence rate increases by $2.2 \%$ given all other variables remain constant.

The observed significant positive effect for the dimension of Neuroticism also seems to be a male phenomenon that prevails despite controlling for one-year-lagged absenteeism, satisfaction in various areas of life as well as subjective health. As the effect is not significant for the female sample $\mathrm{H} 2$ cannot be universally supported.

For more conscientious employees we generally observe a lower probability of being absent at least one day supporting the validity of $\mathrm{H} 3$. The coefficients are significant at least at the $5 \%$ level in the total and the female sample in both specifications. Interestingly, we do not obtain significant results for the male sample.

Further, we observe a significant negative effect of Agreeableness on the attendance decision for the total and the male sample which is in line with $\mathrm{H} 4$. The marginal effect in specification (2) indicates that an increase in the Agreeableness score by one standard deviation leads to an average $2.3 \%$ decline in the absence propensity rate among male employees. 
Table 2: Results of the Logit regression (Marginal effects)

\begin{tabular}{|c|c|c|c|c|c|c|}
\hline \multirow{2}{*}{ VARIABLES } & \multicolumn{3}{|c|}{ Specification (1) } & \multicolumn{3}{|c|}{ Specification (2) } \\
\hline & Total & Female & Male & Total & Female & Male \\
\hline \multirow[t]{2}{*}{ Extraversion } & 0.0093 & -0.0044 & $0.0211^{*}$ & 0.0117 & 0.0001 & $0.0217^{*}$ \\
\hline & $(0.0087)$ & $(0.0127)$ & $(0.0120)$ & $(0.0089)$ & $(0.0133)$ & $(0.0124)$ \\
\hline \multirow[t]{2}{*}{ Neuroticism } & $0.0165 * *$ & 0.0057 & $0.0269 * *$ & $0.0209 * *$ & 0.0106 & $0.0297 * *$ \\
\hline & $(0.0084)$ & $(0.0117)$ & $(0.0121)$ & $(0.0087)$ & $(0.0124)$ & $(0.0126)$ \\
\hline \multirow[t]{2}{*}{ Conscientiousness } & $-0.0221 * *$ & $-0.0275 * *$ & -0.0169 & $-0.0193 * *$ & $-0.0299 * *$ & -0.0143 \\
\hline & $(0.0090)$ & (0.0135) & $(0.0120)$ & $(0.0093)$ & $(0.0143)$ & $(0.0126)$ \\
\hline \multirow[t]{2}{*}{ Agreeableness } & $-0.0197 * *$ & -0.0180 & $-0.0201 *$ & $-0.0166 *$ & -0.0048 & $-0.0231 * *$ \\
\hline & $(0.0084)$ & $(0.0126)$ & $(0.0114)$ & $(0.0086)$ & $(0.0132)$ & $(0.0117)$ \\
\hline \multirow[t]{2}{*}{ Openness } & 0.0136 & $0.0213^{*}$ & 0.0070 & 0.0097 & 0.0184 & 0.0017 \\
\hline & $(0.0085)$ & $(0.0121)$ & $(0.0119)$ & $(0.0088)$ & $(0.0128)$ & $(0.0125)$ \\
\hline \multirow[t]{2}{*}{ Health } & $-0.0137 * * *$ & $-0.0110 *$ & $-0.0166 * * *$ & $-0.0172 * * *$ & $-0.0132 *$ & $-0.0230 * * *$ \\
\hline & $(0.0044)$ & $(0.0062)$ & $(0.0063)$ & $(0.0051)$ & $(0.0073)$ & $(0.0075)$ \\
\hline \multirow[t]{2}{*}{ Absent04 } & $0.3900 * * *$ & $0.3945^{* * *}$ & $0.3884^{* * *}$ & $0.3694^{* * *}$ & $0.3597 * * *$ & $0.3798 * * *$ \\
\hline & $(0.0134)$ & (0.0196) & $(0.0185)$ & $(0.0140)$ & $(0.0212)$ & $(0.0192)$ \\
\hline \multirow[t]{2}{*}{ Female } & -0.0011 & _ & & 0.0269 & 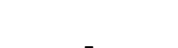 & _ \\
\hline & $(0.0164)$ & - & & $(0.0203)$ & & \\
\hline \multirow[t]{2}{*}{ Age } & & & & $-0.0169 * *$ & -0.0145 & $-0.0173^{*}$ \\
\hline & & & & $(0.0072)$ & $(0.0106)$ & $(0.0103)$ \\
\hline \multirow[t]{2}{*}{$\mathrm{Age}^{2}$} & & & & $0.0002 * *$ & 0.0001 & 0.0002 \\
\hline & & & & $(0.0001)$ & $(0.0001)$ & $(0.0001)$ \\
\hline \multirow[t]{2}{*}{ Married } & & & & $-0.0338^{*}$ & $-0.0636 * *$ & -0.0008 \\
\hline & & & & $(0.0199)$ & $(0.0276)$ & $(0.0302)$ \\
\hline \multirow[t]{2}{*}{ Child } & & & & -0.0084 & -0.0135 & -0.0059 \\
\hline & & & & $(0.0193)$ & $(0.0293)$ & $(0.0273)$ \\
\hline \multirow{2}{*}{\multicolumn{2}{|c|}{ Hauptschule ( 9 years of school) }} & & & 0.0740 & 0.0129 & 0.1273 \\
\hline & & & & $(0.0740)$ & $(0.1113)$ & $(0.1009)$ \\
\hline \multirow{2}{*}{\multicolumn{2}{|c|}{ Realschule (10 years of school) }} & & & 0.0530 & 0.0130 & 0.0963 \\
\hline & & & & $(0.0762)$ & $(0.1124)$ & $(0.1045)$ \\
\hline \multirow{2}{*}{\multicolumn{2}{|c|}{ Fachabi (12 years of school) }} & & & 0.1193 & 0.0689 & 0.1511 \\
\hline & & & & $(0.0747)$ & $(0.1175)$ & $(0.0993)$ \\
\hline \multirow{2}{*}{\multicolumn{2}{|c|}{ Abi (13 years of school) }} & & & 0.0962 & 0.0876 & 0.0954 \\
\hline & & & & $(0.0758)$ & $(0.1113)$ & $(0.1062)$ \\
\hline \multirow{2}{*}{\multicolumn{2}{|c|}{ Other school leaving certificate }} & & & 0.0442 & -0.0196 & 0.0961 \\
\hline & & & & $(0.0781)$ & $(0.1190)$ & $(0.1039)$ \\
\hline \multirow{2}{*}{\multicolumn{2}{|c|}{ Vocational Qualification }} & & & -0.0223 & -0.0068 & -0.0390 \\
\hline & & & & $(0.0220)$ & $(0.0324)$ & $(0.0308)$ \\
\hline University degree & & & & $-0.0473 *$ & $-0.0666 *$ & -0.0392 \\
\hline & & & & $(0.0270)$ & $(0.0389)$ & $(0.0392)$ \\
\hline Contractual workin & hours & & & $0.0039 * * *$ & $0.0033^{* * *}$ & $0.0027^{*}$ \\
\hline & & & & $(0.0009)$ & $(0.0012)$ & $(0.0014)$ \\
\hline Wage per hour & & & & -0.0002 & 0.0037 & $-0.0028^{*}$ \\
\hline & & & & $(0.0014)$ & $(0.0025)$ & $(0.0017)$ \\
\hline White collar worke & & & & -0.0049 & -0.0511 & 0.0506 \\
\hline & & & & $(0.0234)$ & $(0.0363)$ & $(0.0319)$ \\
\hline Civil servant & & & & 0.0560 & 0.0137 & $0.0919 *$ \\
\hline & & & & $(0.0376)$ & $(0.0632)$ & $(0.0495)$ \\
\hline Tenure & & & & -0.0004 & 0.0018 & -0.0023 \\
\hline & & & & $(0.0030)$ & $(0.0046)$ & $(0.0041)$ \\
\hline
\end{tabular}


Table 2 (continued): Results of the Logit regression (Marginal effects)

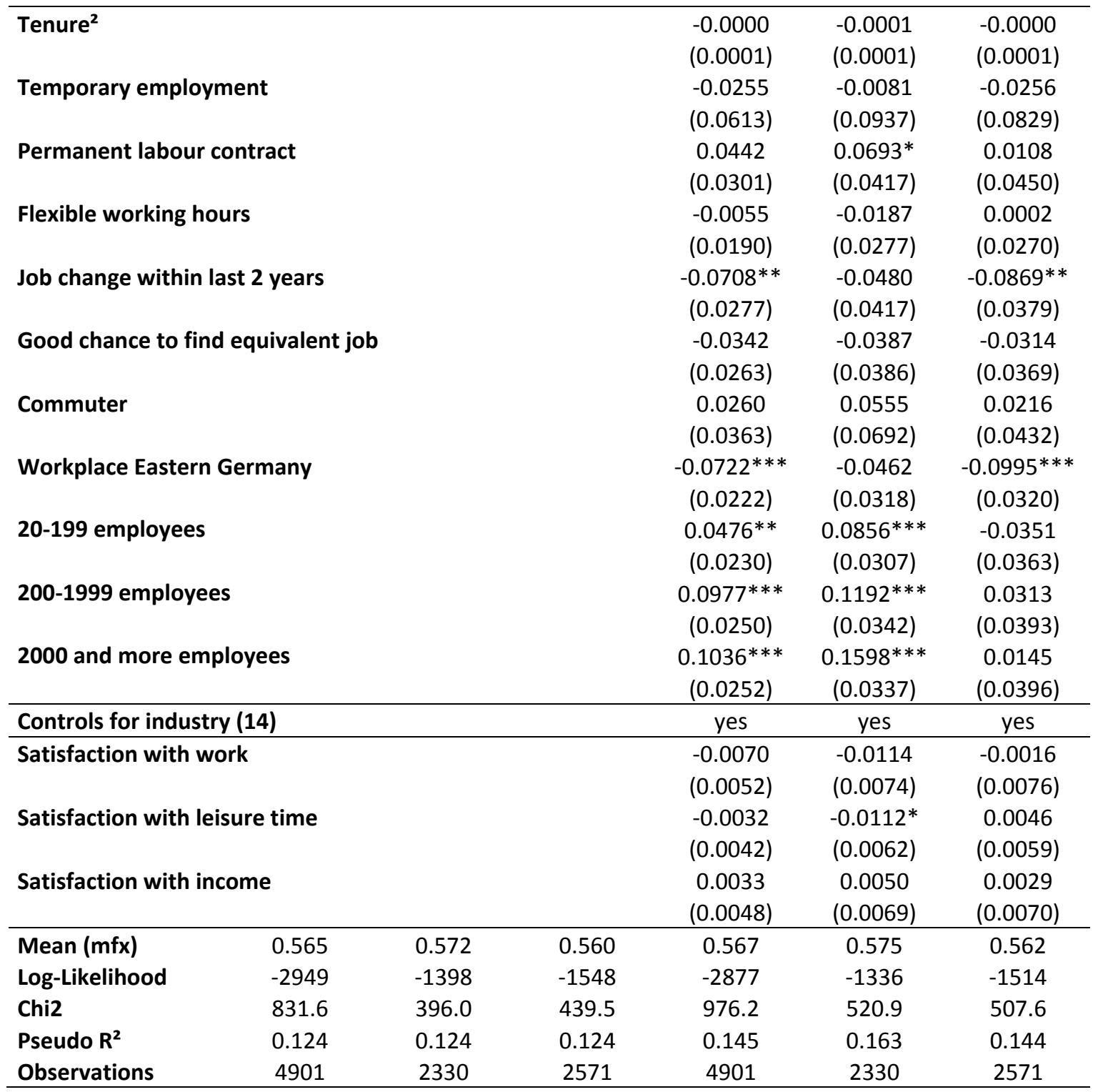

Notes: Own calculations with GSOEP 2004-2006. Dependent variable is Absent 05. Displayed are marginal effects at the mean. ${ }^{* * *}\left(* *,{ }^{*}\right)$ : Coefficient is significant at $1 \%(5 \%, 10 \%)$ level. Reference groups are "no school leaving certificate", "no vocational qualification", "blue-collar worker", "1-19 employees", "service sector".

The results do not suggest any significant influence of the factor Openness in the full model. ${ }^{9}$ As expected we find a significant negative effect of the health variable on absenteeism, i.e. employees that are on average or above satisfied with their health condition have a smaller propensity to be absent at all, but the effect size being similar

\footnotetext{
${ }^{9}$ A detailed analysis of the influence of this personality dimension on work attendance along the predictions following from the socio-psychological literature requires an analysis on the occupational level to account for the different job characteristics. A first analysis by broad occupational groups (bluecollar, white-collar, public servants) did not yield any significant influence of this dimension on absenteeism; a detailed analysis is beyond the scope of this article.
} 
to those of the personality effects described above. This is a striking finding from our point of view and is discussed in more detail below.

To investigate if the underlying mechanisms affecting the probability to be absent at all and the number of days absent are the same, the results of the Negative Binomial Analysis displayed in Table 3 are inspected next.

Table 3: Results of the Negative Binomial Regression

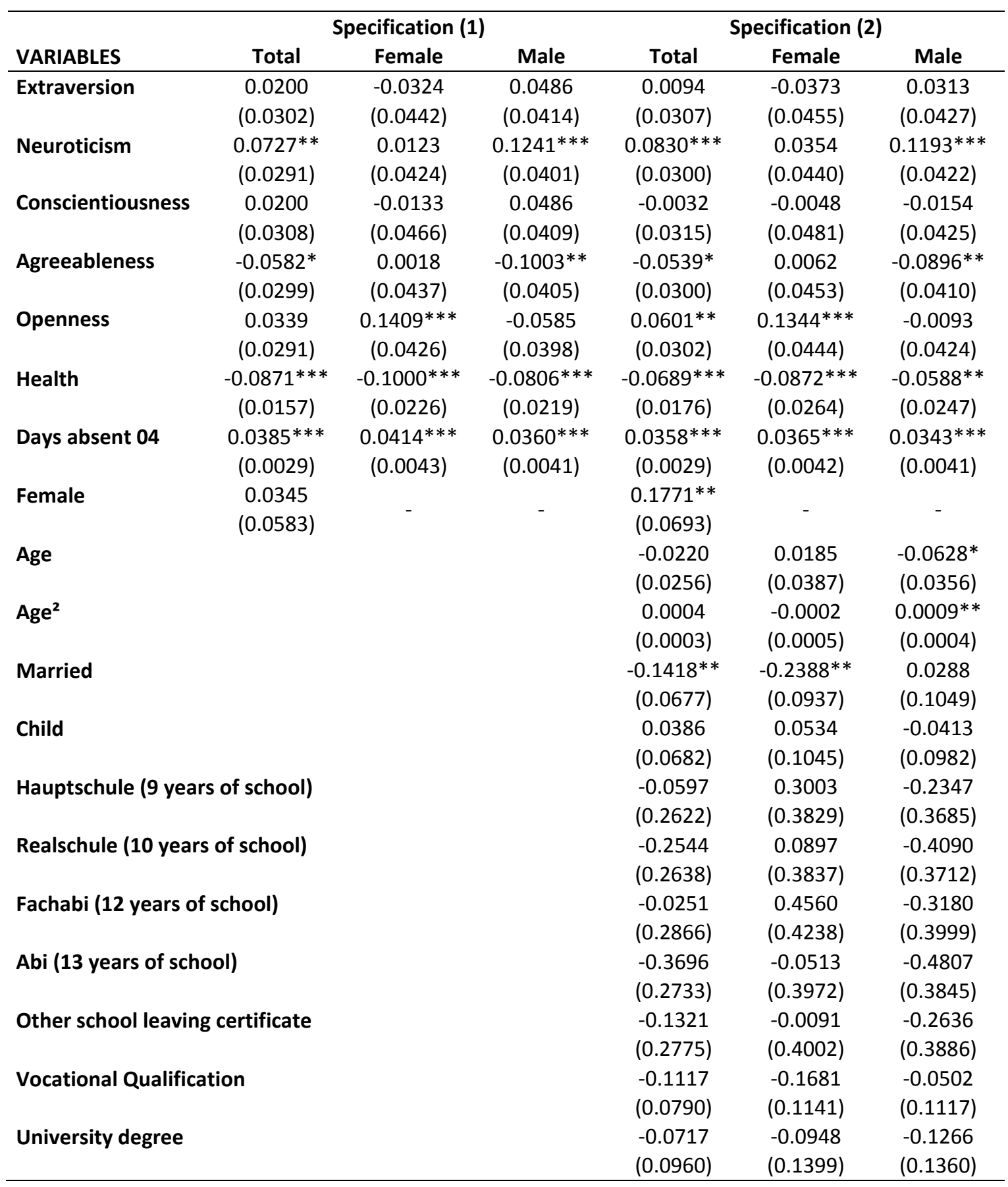


Table 3 (continued): Results of the Negative Binomial Regression

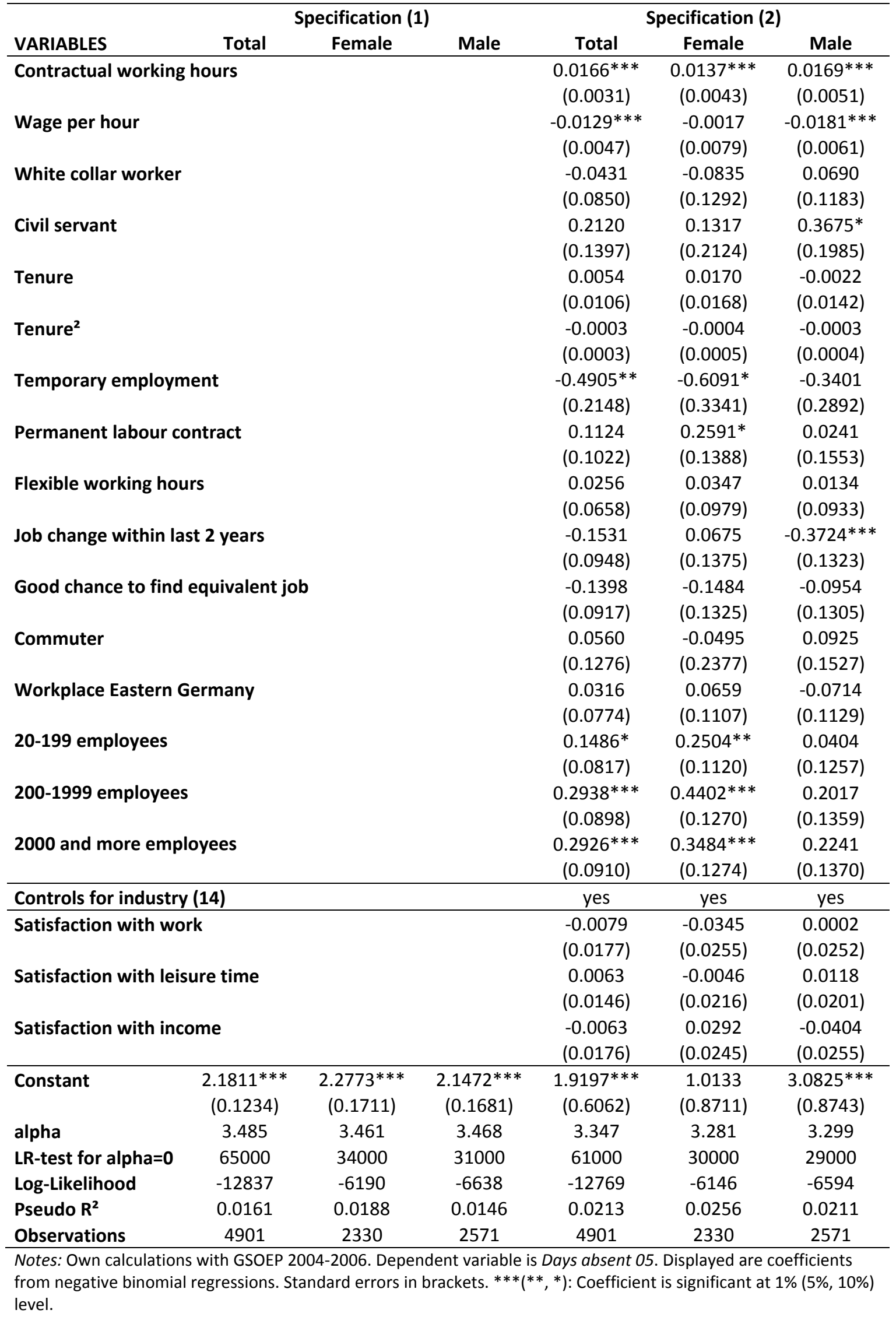


First, we find that the parameter $\alpha$ is in all specifications significantly different from zero. Likelihood ratio tests for overdispersion strongly reject the null hypothesis $(\alpha=0)$ at all levels of significance which shows that the Negbin model should be preferred to the Poisson model.

When reviewing the coefficients of the distinct personality dimensions we find that the Neuroticism coefficients indicate a highly significant positive effect on absenteeism for the total and the male sample. According to the results of the full model, an increase on the Neuroticism scale by one standard deviation results in an average increase of the number of days absent by about $11.9 \%$ ( 0.67 days) for men. One could argue that the effect of Neuroticism is the result of an underlying health effect. We accounted for this by conducting a mediation analysis using the Sobel test (Baron/Keeney 1986). The test yield for the male sample that $17.65 \%$ of the total effect of Neuroticism on absenteeism is mediated by the health variable, indicating that a substantial part of more than $80 \%$ of the effect goes back to the impact of the personality dimension itself. In line with $\mathrm{H} 2$ and the results of the Logit analysis we find Neuroticism to be an important indicator of absenteeism despite health effects, especially for male employees.

According to the Extraversion coefficients the positive influence of this distinct personality dimension on absenteeism as observed for the male sample in the Logit model cannot be confirmed regarding the number of days absent and $\mathrm{H} 1$ has to be rejected.

Also, $\mathrm{H} 3$ on the negative influence of Conscientiousness on absenteeism does not hold regarding the number of days absent. Consequently, this dimension is rather an important determinant of absence occurrence, but does not affect the length of absence.

In contrast, the negative influence of Agreeableness on absenteeism is confirmed for the total and the male sample. A male scoring one standard deviation higher on the Agreeableness scale than a comparable man is according to specification (2) about $9 \%$ less days absent which sums to half a day on average. 
The Negbin II results further indicate a highly significant positive effect of Openness on the number of days absent for women. The magnitude of the effect amounts on average to an additional 0.82 days of absence for a woman if her Openness score increases by one standard deviation.

As for the occurrence of absenteeism a significant negative effect of the health variable and a significant positive effect of the lagged absenteeism variable is also present with respect to the duration of absenteeism in all samples. The effect size is even smaller than the effect of the personality factors described which shows the significance of personality as determinant of absenteeism.

To challenge the assumption of a linear relationship between the values of the personality traits and absenteeism we employ the approach suggested by Mueller and Plug (2006) and conduct all analyses for the top and bottom $25 \%$ of all personality dimensions. If any impact of personality on absenteeism is driven by extreme values of the respective personality dimensions we might find an effect for those personality dimensions where specifications assuming linear personality scores attenuate an effect at the mean of the variables to zero. Essentially, most effects are found to be significant only for high scorers on the respective personality scales and only for those personality dimensions where we identified a significant impact on the average probability to be absent or the days of absence, respectively, which shows the robustness of the results in our preferred specification. ${ }^{10}$

As a further check of robustness we accounted for possible differences regarding the labour market participation of women by estimating Heckman selection Probit models with the result that the analysis did not yield significant differences in the findings.

To sum up, personality matters as a significant influencing factor on the incidence of absence as well as the number of days absent. When reviewing the effects of the distinct personality dimensions on absenteeism we observe that (1) extraverted male employees exhibit higher probabilities of absence incidence but Extraversion does not affect the number of days absent. (2) Neurotic male workers show higher

\footnotetext{
${ }^{10}$ The results can be obtained by the authors on request.
} 
absenteeism rates and a higher number of days absent. (3) Conscientious female employees exhibit lower probabilities to be absent at least one day, while the dimension of Conscientiousness does not influence the number of days absent. (4) Agreeable male employees have a lower probability of absence incidence as well as less days absent. (5) Openness to Experience has a significant positive effect on the number of days absent among women.

\section{Discussion}

The aim of this study is to establish if and how personality traits as measured in the Big Five framework influence work attendance using representative data. Although the empirical results do not suggest an unrestricted impact of all Big Five dimensions for men and women, we observe significant personality effects on attendance behaviour especially for male employees.

Linking personality trait theory to economic theory suggests that personality traits influence individual preferences (Borghans et al., 2008). In turn, preferences influence hedonic labour market outcomes (Rosen, 1986; Delgado and Kniesner, 1997), individual levels of sickness in shirking models (Barmby et al., 1994) and individual work-leisure preferences (Allen, 1981). As we have discussed above, a number of explanatory concepts could be applied when explaining the influence of personality on attendance decisions. Still, we want to provide some intuitive explanations for our findings.

The fact that we cannot reject the null hypothesis of no influence in the case of $\mathrm{H} 1$ - at least in the Negbin estimates - might be explained by counteracting influences of the Extraversion personality trait which offset a significant positive effect on absenteeism. Such a counteracting influence in the light of $\mathrm{H} 1$ is evidence that extraverts earn more, are promoted more frequently and experience higher levels of satisfaction in their work, careers and lives (Seibert and Kraimer, 2001). However, due to the positive affection and emotionality of extraverts they tend to approach their environment proactively when they are dissatisfied, trying to shape their work environment in an active manner (Seibert et al., 1999). Taking additional leisure time 
when needed might help to perform successfully. This is in line with Steers and Rhodes (1978) who propose that absenteeism can also be efficient when it allows employees to relax from stressful work and increase their performance afterwards. It becomes obvious that the mixed evidence makes it difficult to reconcile the arguments.

Explaining the observed positive effect of Neuroticism seems obvious when thinking of the tendency of neurotic (overcommitted) people to become ill for physical and especially mental reasons (Vearing and Mak, 2007). However, a positive effect of the personality trait Neuroticism on absenteeism is present when controlling for the subjective health status. We have shown that the effect of Neuroticism is partly mediated by the health variable but more than $80 \%$ of the effect goes back to the impact of the personality dimension itself. We still consider two possible ways of an interaction between Neuroticism and the health variable. First, the true health status might be underreported in the subjective health variable in our data set which would explain our results consistent with Vearing and Mak (2007). Second, neurotic employees experience a psychic distress which interferes with their attendance decision but is not manifested in the health status. The latter explanation is more in line with higher absenteeism due to motivational reasons rather than absenteeism caused directly by health problems. We find clear support for $\mathrm{H} 2$ for men.

It is conceivable that conscientious employees exhibit lower absenteeism rates in general because of having a greater sense of responsibility. The fact that we cannot find a significant impact of Conscientiousness on the number of days absent can be the result of differing critical levels of sickness (Barmby et al., 1994) and the idea that individual recovery time after illness is not necessarily dependant on the degree of Conscientiousness.

According to the derivation of $\mathrm{H} 4$ the negative influence of Agreeableness could be due to the higher normative commitment of agreeable employees as they feel a greater obligation towards their organization and thus might avoid counterproductive behaviour such as absenteeism.

From a research point of view the evidence presented - based on representative data for Germany - suggests personality as an important determinant of 
individual work attendance. It is particularly striking that the significant personality traits exhibit similar effect sizes in specifications (1) and (2). This suggests including personality as an important explanatory factor for absenteeism in addition to information on personal and workplace characteristics. Moreover, the fact that we found evidence in line with the predictions from social psychology for single personality factors demonstrates the strength of the Big Five personality scale as a predictor to important outcomes of work life (Heckman et al., 2006).

However, our conclusions rest on the validity of the brief self-report personality measure used in the GSOEP which is prone to measurement error according to Borghans et al. (2008). Measurement error in the explanatory variable leads to attenuated effect estimates which underscore the importance of the economically and statistically significant effects for the single scores of the Big Five. Thereby, our results meet objections presented by Borghans et al. (2008) that a correlation between broad personality measures like a single score for the Big Five personality traits (opposed to scores on subordinated facets) and economic outcomes is not to be expected. Our results encourage the inclusion of measures of personality to explain part of the unobservable in empirical studies of economic outcomes using large representative household samples.

Our findings augment previous results on the link between personality and absenteeism by analyzing representative data and including a huge set of control variables typically not available in small scale surveys. Our findings have implications for practitioners in personnel departments by supporting the evidence presented in case studies that the Big Five personality tests used in personnel assessment and selection could be also valuable to learn about absenteeism behaviour of employees and not only integrity test as previous research has shown (Ones et al., 2003). Using personality tests as a screening device concerning employees' absenteeism behaviour requires further research on the link between a Big Five personality assessment and absenteeism at the firm level taking also the matching of workers to specific jobs into account. 
We find striking differences in the influence of personality on absenteeism between men and women. The observed influence on men is significantly higher than that on women. This issue deserves a more detailed investigation in future research. Promising fields are the research on sex-roles and stereotyping which have to be linked closer to economic research in the future.

We are confident that the effects obtained in our estimates have practical significance when thinking of the high estimated costs of absenteeism. 


\section{Acknowledgements}

We would like to thank participants at the Brownbag Seminar in Microeconomics at the University of Cologne, the 6th Annual Meeting of AKempor and the 3rd Conference of Non-Cognitive Skills for their comments on earlier versions of the paper. In particular, we are indebted to Dorothea Alewell, Christiane Schäfer, Dirk Sliwka, Achim Wambach, Ingo Weller and Rainer Winkelmann for their valuable comments. All remaining errors are our own.

\section{References}

Allen, S.G. (1981) An Empirical Model of Work Attendance, The Review of Economics and Statistics, 63, 77-87.

Barmby, T.A., Nolan, M. and Winkelmann, R. (2001) Contracted Workdays and Absence, The Manchester School, 69, 269-75.

Barmby, T.A. and Treble, J.G. (1991) Absenteeism in a Medium-Sized Manufacturing Plant, Applied Economics, 23, 161-66.

Barmby, T.A., Orme, C.D. and Treble, J.G. (1991) Worker Absenteeism: An Analysis using Microdata, The Economic Journal, 101, 214-29.

Barmby, T.A., Sessions, J.G. and Treble, J.G. (1994) Absenteeism, Efficiency Wages and Shirking, Scandinavian Journal of Economics, 96, 561-66.

Baron, R.M. and Keeney, D.A. (1986) The moderator-mediator variable distinction in social psychological research: Conceptual, strategic, and statistical considerations, Journal of Personality and Social Psychology, 51, 1173-82.

Barrick, M.R. and Mount, M.K. (1991) The Big Five Personality Dimensions and Job Performance: A Meta-Analysis, Personnel Psychology, 44, 1-26.

Borghans, L., Duckworth, A.L., Heckman, J.J. and ter Weel, B. (2008) The Economics and Psychology of Personality Traits, Journal of Human Resources, 43, 972-1059.

Cameron, A.C. and Trivedi, P.K. (2005) Microeconometrics, Cambridge University Press, Cambridge. 
Cameron, A.C. and Trivedi, P.K. (1998) Regression analysis of count data. Cambridge University Press, Cambridge.

Caspi, A. (1999) Personality development across the life course, in Handbook of Child Psychology, Vol. 3, Social, emotional and personality development, $2^{\text {nd }}$ edition, (Ed) W. Damon, John Wiley \& Sons, New York, 311-88.

Cohen, A. and Golan, R. (2007) Predicting absenteeism and turnover intentions by past absenteeism and work attitudes, Career Development International, 12, 416-32.

Costa, P.T. and McCrae, R.R. (1992) NEO-PI-R Professional manual. Psychological Assessment Resources, Odessa.

Costa, P.T., Terracciano, A. and McCrae, R.R. (2001) Gender Differences in Personality Traits Across Cultures: Robust and Surprising Findings, Journal of Personality and Social Psychology, 81, 322-31.

Darviri, S.V. and Woods, S.A. (2006) Uncertified absence from work and the Big Five: An examination of absence records and future absence intentions, Personality and Individual Differences, 41, 359-69.

Delgado, M.A. and Kniesner, T.J. (1997) Count Data Models with Variance of Unknown Form: An Application to a Hedonic Model of Worker Absenteeism, Review of Economics and Statistics, 79, 41-9.

Destatis (Federal Statistical Office Germany) (2009) Gesundheit - Ausgaben, 19952007. Available at https://wwwec.destatis.de/csp/shop/sfg/bpm.html.cms.cBroker.cls?cmspath=struktur,vollanzeige.c spandID=1023844 (accessed 16 March 2010).

Erdheim, J., Wang, M. and Zickar, M.J. (2006) Linking the Big Five personality constructs to organizational commitment, Personality and Individual Differences, 41, 959-70.

Gerlitz, J.Y. and Schupp, J. (2005) Zur Erhebung der Big-Five-basierten Persönlichkeitsmerkmale im SOEP, in DIW Berlin, Research Notes. Available at http://www.diw.de/documents/publikationen/73/diw_01.c.43490.de/rn4.pdf (accessed 16 March 2010).

Goldberg, L. R. (1981) Language and individual differences: The search for universals in personality lexicons, in Review of Personality and Social Psychology, Vol. 2, (Ed.) L. 
Wheeler, Sage, Beverly Hills, 141-65.

Greene, W. (2008) Econometric Analysis, $6^{\text {th }}$ edition, Prentice Hall, New Jersey.

GSOEP (2005) Individual question form 2005. Available at

http://panel.gsoep.de/soepinfo2008/ (accessed 23 April 2010).

Harrison, D.A. and Martocchio, J.J. (1998) Time for Absenteeism: A 20-Year Review of Origins, Offshoots, and Outcomes, Journal of Management, 24, 305-50.

Heckman, J. J., Stixrud, J. and Urzua, S. (2006) The Effects of Cognitive and Noncognitive Abilities on Labor Market Outcomes and Social Behavior, Journal of Labor Economics, 24, 411-482.

Heineck, G. and Anger, S. (2008) The Returns to Cognitive Abilities and Personality Traits in Germany, SOEPpapers on Multidisciplinary Panel Data Research, No. 124. Available at http://www.diw.de/documents/publikationen/73/diw_01.c.88528.de/diw_sp0124.pdf (accessed 16 March 2010).

Hogan, J. and Ones, D.S. (1997) Conscientiousness and Integrity at Work, in Handbook of Personality Psychology, (Eds) R. Hogan, J.A. Johnson and S. Briggs, Academic Press, San Diego, 849-70.

John, O.P. and Srivastava, S. (1999) The Big Five Trait Taxonomy: History, Measurement, and Theoretical Perspectives, in Handbook of personality: Theory and research, (Eds) L.A. Pervin and O.P. John, Guilford Press, New York, 102-38.

Judge, T.A., Martocchio, J.J. and Thoresen, C.J. (1997) Five-Factor Model of Personality and Employee Absence, Journal of Applied Psychology, 82, 745-55.

Markussen, S., Røed, K., Røgeberg, O.J. and Gaure, S. (2009) The Anatomy of Absenteeism, IZA Discussion Paper, No. 4240. Available at http://ftp.iza.org/dp4240.pdf (accessed 26 April 2010).

Martocchio, J.J. and Harrison, D.A. (1993) To be there or not to be there? Questions, theories, and methods in absenteeism research, Research in Personnel and Human Resources Management, 11, 259-328.

McAdams, D.P. (2006) The Person: A New Introduction to Personality Psychology, 4th ed., Wiley, Hoboken. 
McCrae, R.R. (1996) Social Consequences of Experiential Openness, Psychological Bulletin, 120, 323-37.

McCrae, R.R. and Costa, P. (2003) Personality in adulthood: A Five-Factor Theory perspective, Vol. 2, Guilford Press, New York.

McCrae, R.R. and John, O.P. (1992) An introduction to the five-factor model and its applications, Journal of Personality, 60, 175-215.

Mueller, G. and Plug, E. (2006) Estimating the effects of personality on male and female earnings, Industrial and Labor Relations Review, 60, 3-22.

Nyhus, E. K. and Pons, E. (2005) The Effects of Personality on Earnings, Journal of Economic Psychology, 26, 363-84.

Ones, D.S., Dilchert, S., Viswesvaran, C. and Judge, T.A. (2007) In support of personality assessment in organizational settings, Personnel Psychology, 60, 995-1027.

Ones, D.S., Viswesvaran, C. and Schmidt, F.L. (2003) Personality and Absenteeism: A Meta-Analysis of Integrity Tests, European Journal of Personality, 17, 19-38.

Pervin, L.A., Cervone, D. and John, O.P. (2005) Personality: theory and research, Wiley, Hoboken.

Porter, L.W. and Steers, R.M. (1973) Organizational, work and personal factors in employee turnover and absenteeism, Psychological Bulletin, 80, 151-76.

Roberts, B.W., Walton, K. and Viechtbauer (2006) Patterns of Mean-Level Change in Personality Traits Across the Life Course: A Meta-Analysis of Longitudinal Studies, Psychological Bulletin, 132, 1-25.

Rosen, S. (1986) Theory of equalizing differences, in Handbook of Labor Economics. (Eds.) O. Ashenfelter and R. Layard, Vol. 1, Elsevier, Amsterdam, 641-92.

Salgado, J.F. (2002) The Big Five Personality Dimensions and Counterproductive Behaviors, International Journal of Selection and Assessment, 10, 117-25.

Seibert, S.E. and Kraimer, M.L. (2001) The Five-Factor Model of Personality and Career Success, Journal of Vocational Behavior, 58, 1-21.

Seibert, S.E., Crant, J.M. and Kraimer, M.L. (1999) Proactive personality and career success, Journal of Applied Psychology, 84, 416-27. 
Sinha, A.K. (1963) Manifest anxiety affecting industrial absenteeism, Psychological Reports, 13, 258.

Steers, R.M. and Rhodes, S.R. (1978) Major Influences on Employee Attendance: A Process Model, Journal of Applied Psychology, 63, 391-407.

Vearing, A. and Mak, A.S. (2007) Big five personality and effort-reward imbalance factors in employees' depressive symptoms, Personality and Individual Differences, 43, 1744-55.

Winkelmann, R. (1999) Wages, firm size and absenteeism, Applied Economics Letters, 6, 337-41.

Winkelmann, R. (1997) Econometric Analysis of Count Data, Springer, Berlin.

Winkelmann, L. and Winkelmann, R. (2008) Personality, Work, and Satisfaction: Evidence from the German Socio-Economic Panel, Journal of Positive Psychology, 3, 266-75. 


\section{Annex}

Table A 1: Items of the Personality Questionnaire BFI-S (GSOEP 2005)

\begin{tabular}{|c|c|}
\hline Conscientiousness & Agreeableness \\
\hline $\begin{array}{l}\text { I see myself as someone who ... } \\
\text { - does a thorough job (C1) } \\
\text { - } \quad \text { tends to be lazy (-) (C2) } \\
\text { - } \quad \text { does things effectively and efficiently (C3) }\end{array}$ & $\begin{array}{l}\text { I see myself as someone who ... } \\
\text { - } \quad \text { is sometimes somewhat rude to others (-) } \\
\text { (A1) } \\
\text { - has a forgiving nature (A2) } \\
\text { - } \quad \text { is considerate and kind to others (A3) }\end{array}$ \\
\hline Neuroticism & Openness to Experience \\
\hline $\begin{array}{l}\text { I see myself as someone who ... } \\
\text { - } \quad \text { worries a lot (N1) } \\
\text { - } \quad \text { gets nervous easily (N2) } \\
\text { - } \quad \text { is relaxed, handles stress well (-) (N3) }\end{array}$ & $\begin{array}{l}\text { I see myself as someone who ... } \\
\text { - } \quad \text { is original, comes up with new ideas (O1) } \\
\text { - } \quad \text { values artistic experiences }(\mathrm{O} 2) \\
\text { - } \quad \text { has an active imagination }(\mathrm{O} 3)\end{array}$ \\
\hline Extraversion & \multirow[b]{2}{*}{$\begin{array}{l}\text { Note: The assessment is based on a seven- } \\
\text { point Likert scale ( } 1 \text { : strongly disagree; } 7 \text { : } \\
\text { strongly agree). A dimensions' value is } \\
\text { calculated as the average of the values of the } \\
\text { corresponding items. Items marked with "(-)" } \\
\text { are negatively poled and reversed for } \\
\text { calculation purposes. }\end{array}$} \\
\hline $\begin{array}{l}\text { I see myself as someone who ... } \\
\text { - } \quad \text { is communicative, talkative (E1) } \\
\text { - } \quad \text { is outgoing, sociable (E2) } \\
\text { - } \quad \text { is reserved (-) (E3) }\end{array}$ & \\
\hline
\end{tabular}

Source: Individual question form GSOEP (2005). Own illustration.

Table A 2: Descriptive statistics of all variables

\begin{tabular}{lrrrr}
\hline VARIABLES & Mean & Std. Dev. & Min & Max \\
\hline Absent 05 & 0.5572 & 0.4968 & 0 & 1 \\
Days absent 05 & 7.3610 & 17.7095 & 0 & 300 \\
Absent 04 & 0.5597 & .4965 & 0 & 1 \\
Days absent 04 & 6.7311 & 14.9660 & 0 & 300 \\
\hline Extraversion & 4.8352 & 1.1047 & 1 & 7 \\
Neuroticism & 3.8356 & 1.1802 & 1 & 7 \\
Conscientiousness & 6.0246 & 0.8203 & 2.3333 & 7 \\
Agreeableness & 5.4145 & 0.9560 & 1.3333 & 7 \\
Openness & 4.4815 & 1.1571 & 1 & 7 \\
\hline Health (Satisfaction with Health 04) & 7.1077 & 1.8249 & 0 & 10 \\
\hline Female & 0.4754 & 0.49945 & 0 & 1 \\
Age & 42.58 & 9.53 & 19 & 65 \\
Age & 1903.913 & 810.1534 & 361 & 4225 \\
Married & 0.6748 & 0.4685 & 0 & 1 \\
Child & 0.3987 & 0.4897 & 0 & 1 \\
Hauptschule (9 years of school) & 0.2418 & 0.4282 & 0 & 1 \\
Realschule (10 years of school) & 0.3742 & 0.4840 & 0 & 1 \\
Fachabi (12 years of school) & 0.0620 & 0.2412 & 0 & 1 \\
Abi (13 years of school) & 0.2467 & 0.4311 & 0 & 1 \\
Other school leaving certificate & 0.0639 & 0.2445 & 0 & 1 \\
Vocational Qualification & 0.7431 & 0.4370 & 0 & 1 \\
University degree & 0.2657 & 0.4417 & 0 & 1 \\
\hline
\end{tabular}


Table A 3 (continued): Descriptive statistics of all variables

\begin{tabular}{lrrrr}
\hline VARIABLES & Mean & Std. Dev. & Min & Max \\
\hline Contractual working hours & 33.6401 & 10.4055 & 0 & 70 \\
Wage per hour & 15.8836 & 8.0687 & 0 & 115.4734 \\
White collar worker & 0.6046 & 0.4890 & 0 & 1 \\
Civil servant & 0.0967 & 0.2956 & 0 & 1 \\
Tenure & 12.1143 & 9.5130 & 0 & 48.8 \\
Tenure & 237.2361 & 332.8650 & 0 & 2381.44 \\
Temporary employment & 0.0178 & 0.1321 & 0 & 1 \\
Permanent labour contract & 0.9106 & 0.2853 & 0 & 1 \\
Flexible working hours & 0.3618 & 0.4806 & 0 & 1 \\
Job change within last 2 years & 0.1171 & 0.3216 & 0 & 1 \\
Good chance to find equivalent job & 0.1126 & 0.3162 & 0 & 1 \\
Commuter (more than 50km) & 0.0516 & 0.2213 & 0 & 1 \\
Workplace Eastern Germany & 0.2095 & 0.4070 & 0 & 1 \\
1-19 employees & 0.2055 & 0.4041 & 0 & 1 \\
20-199 employees & 0.3042 & 0.4601 & 0 & 1 \\
200-1999 employees & 0.2300 & 0.4208 & 0 & 1 \\
2000 and more employees & 0.2604 & 0.4389 & 0 & 1 \\
Agriculture, forestry and fish farming & 0.0092 & 0.0954 & 0 & 1 \\
Mining & 0.0261 & 0.1595 & 0 & 1 \\
Textile-, leather, wood-working ind. & 0.0296 & 0.1695 & 0 & 1 \\
Chemical industry and rubber & 0.0371 & 0.1891 & 0 & 1 \\
Metal industry & 0.0602 & 0.2379 & 0 & 1 \\
Machine- and vehicle construction & 0.0718 & 0.2582 & 0 & 1 \\
Electronic industry & 0.0486 & 0.2150 & 0 & 1 \\
Food industry & 0.0151 & 0.1220 & 0 & 1 \\
Building industry & 0.0461 & 0.2098 & 0 & 1 \\
Trade & 0.1137 & 0.3174 & 0 & 1 \\
Transportation & 0.0504 & 0.2188 & 0 & 1 \\
Financial services & 0.2098 & 0.4072 & 0 & 1 \\
Service sector & 0.0498 & 0.2175 & 0 & 1 \\
Non-Profit-Organisations & 0.2326 & 0.4225 & 0 & 1 \\
\hline Satisfaction with work & 7.1134 & 1.8537 & 0 & 10 \\
Satisfaction with leisure time & 6.5407 & 2.0271 & 0 & 10 \\
Satisfaction with income & 6.3807 & 2.0631 & 0 & 10 \\
\hline Sourc: GSOEP (203-2006) & & & & \\
\hline
\end{tabular}

Source: GSOEP (2003-2006). N=4901. 